\title{
Infrared Spectroscopy of Titania Sol-Gel Coatings on 316L Stainless Steel
}

\author{
Daniela Cordeiro Leite Vasconcelos ${ }^{1}$, Vilma Conceição Costa $^{1}$, Eduardo Henrique Martins Nunes ${ }^{1}$, \\ Antônio Claret Soares Sabioni ${ }^{2}$, Massimo Gasparon ${ }^{3}$, Wander Luiz Vasconcelos ${ }^{1^{*}}$
}

${ }^{1}$ Department of Metallurgical and Materials Engineering, Federal University of Minas Gerais, Belo Horizonte, Brasil; ${ }^{2}$ Department of Physics, Federal University of Ouro Preto, Ouro Preto, Brasil; ${ }^{3}$ School of Earth Sciences, The University of Queensland, St. Lucia, Australia.

Email: ${ }^{*} w l v @$ demet.ufmg.br

Received September $28^{\text {th }}, 2010$; revised December $10^{\text {th }}, 2010$; accepted March $20^{\text {th }}, 2011$.

\begin{abstract}
Sol-gel titania films were deposited on 316 Ltainless steel using titanium isopropoxide as a chemical precursor. Dipcoating was performed at withdrawal speeds of $6 \mathrm{~mm} / \mathrm{min}, 30 \mathrm{~mm} / \mathrm{min}$, and $60 \mathrm{~mm} / \mathrm{min}$. Deposited gel films were heat treated in air at $80^{\circ} \mathrm{C}, 100^{\circ} \mathrm{C}, 300^{\circ} \mathrm{C}$, and $400^{\circ} \mathrm{C}$. The structural evolution of the coatings was evaluated by infrared reflection-absorption spectroscopy. The influence of the withdrawal speed and the heat treatment temperature on the structure of the films was studied by varying the reflectance incidence angle during the infrared experiments and by Glow Discharge Spectrometry. Free functional groups were detected. The results indicate the formation of bidendate bridging coordination of carboxylic acid to titanium. Titanium atoms can also be pentacoordinated according to the processing conditions of the films. We observed a tendency of increasing amounts of OH groups with decreasing reflectance incidence angle. The film hardness was measured via Knoop microindenation hardness test.
\end{abstract}

Keywords: Films, Sol-Gel, Infrared Spectroscopy, Glow Discharge Spectrometry, Knoop Hardness

\section{Introduction}

There are many different thin film processing techniques, including physical and chemical techniques. Among these, sol-gels offer potential advantages [1,2], including the good homogeneity of the product, and the fine control over composition. Another convenient feature of this technology is the fact that sol-gel samples can be obtained as bulks, thin films, and powders $[3,4]$.

Oxide coatings are the most investigated coating systems [5-8]. One advantage of the wet coating technique is that molecular structures, developed by chemical synthesis, can be used to develop new properties either to preserve theses structures on the surface, or to develop new desired molecular structures by heat-treatment and subsequent chemical reaction on the surface. The application potential results from the opportunity of synthesizing unique material properties and combine it with cost-effective coating techniques [9].

The coating of metallic surfaces by sol-gel films has been proposed as a useful way to protect them from oxidation and chemical attack [10-14]. Izumi et al. [15] reported an increase in chemical resistance of aluminized steel sheets coated with sol-gel silica and zirconia, in a $5 \% \mathrm{NaCl}$ solution. Using tetraethylorthosilane as the start material, Vasconcelos et al. [10] obtained sol-gel silica/ 304 stainless steel composites with higher corrosion resistance in a $1 \mathrm{~N} \mathrm{H}_{2} \mathrm{SO}_{4}$ and $3.5 \% \mathrm{NaCl}$ medium. Based on Rutherford Backscattering Spectroscopy data, the authors concluded that the intermediate layer formed between the silica film and the steel substrate is responsible for the increase of the corrosion resistance of the stainless steel. Atik et al. [16] studied the corrosion improvement of 316 steel using titania-silica and alumina-silica sol-gel films. They observed that the coatings allowed a remarkable increase of the stainless steel lifetime when placed in a $3 \% \mathrm{NaCl}$ solution. Titania $\left(\mathrm{TiO}_{2}\right)$ films have attracted attention as photoelectrode, photocatalyst, gas sensor and biomaterial, when used for coating titanium alloys or $316 \mathrm{~L}$ stainless steel.

In this work, we report the preparation of titania gel coatings on $316 \mathrm{~L}$ steel substrates from the hydrolysis and polycondensation of titanium isopropoxide. We shall investigate the effect of the withdrawal speed and heat treatment temperature on the film structure by means of 
reflectance-absorbance infrared spectrometry using variable reflectance incidence angles $(\theta)$. Some important information about bonding and coordination modes of the films is provided by Fourier Transform Infrared Spectroscopy (FTIR). The results of Knoop microindentation tests are then compared with those obtained by FTIR and Glow Discharge Spectrometry (GDS) analyses.

\section{Experimental Procedure}

Titanium dioxide solutions were prepared by hydrolysis and condensation of titanium isopropoxide, $\mathrm{Ti}\left(\mathrm{OC}_{3} \mathrm{H}_{7}\right)_{4}$, (TIP). Ethanol $\left(\mathrm{C}_{2} \mathrm{H}_{5} \mathrm{OH}\right)$ was used as the solvent. The molar ratio $\mathrm{C}_{2} \mathrm{H}_{5} \mathrm{OH} / \mathrm{TIP}$ used was 16 or 64 . Acetic acid $(\mathrm{HAc})$ and diethanolamine were added to the initial solution, using the molar ratio of TIP/HAc $=1$.

The films were deposited by dip-coating from the prepared batch solution on polished sheets of stainless steel $316 \mathrm{~L}$ previously cleaned with water, detergent and acetone. The film deposition was performed by dipping the substrate in the sol and withdrawing it at speeds of 6 $\mathrm{mm} / \mathrm{min}, 30 \mathrm{~mm} / \mathrm{min}$, and $60 \mathrm{~mm} / \mathrm{min}$. After deposition, the films were heat treated in air for 30 minutes at $80^{\circ} \mathrm{C}$, $100^{\circ} \mathrm{C}, 300^{\circ} \mathrm{C}$, and $400^{\circ} \mathrm{C}$.

The coating thicknesses were experimentally estimated considering the withdrawal speeds and the heating temperature. FTIR spectra of the sol-gel derived films were recorded using a Perkin Elmer FTIR Paragon-1000. Reflection-absorption spectra at different angles of incidence were measured using a variable angle specular reflectance (VASR) accessory. This technique is most useful in applications requiring specular reflectance spectra on thin films and allows investigation of the sample in depth layers by varying the incidence angle of the infrared beam. Spectra were collected with a $4 \mathrm{~cm}^{-1}$ resolution and 64 scans were accumulated for each spectrum. In this arrangement the incidence angles are defined with respect to the normal to the sample surface.

The chemical profile composition (varying from the outermost surface towards the substrate) of the titania composite was evaluated by GDS (depth resolved, radio frequency glow discharge atomic emission spectrometry), using a Jobin-Yvon 5000RF. The elements analyzed in this work were $\mathrm{Ti}, \mathrm{O}, \mathrm{Fe}, \mathrm{Cr}, \mathrm{Ni}, \mathrm{Si}$ and $\mathrm{Mn}$. The tested surface area of the samples was approximately $12.5 \mathrm{~mm}^{2}$. After each analysis the samples were transferred to a diamond stylus profilometer (Tencor $\mathrm{P}-10$,) in order to determine the size of the crater formed. For each sample, the time analysis was converted to depth by multiplication of the size of the crater and the average sputter rate.

The film hardness was obtained by performing a microindentation hardness test, using a Future Tech FM-1
Knoop indenter, and $10 \mathrm{~g}$ load with a dwell time of $15 \mathrm{~s}$.

\section{Results and Discussion}

The determination of the structure of the deposited films is discussed in terms of the withdrawal speed, the heating temperature and the incidence angle $(\theta)$ used in the infrared spectroscopy.

In order to estimate the thickness of the $\mathrm{TiO}_{2}$ films, the mass of the coatings and the area of the substrate were measured and the density of an equivalent unsupported film was determined by helium picnometry. The estimated values for thickness range from $120 \mathrm{~nm}$ to $800 \mathrm{~nm}$. The influence of the withdrawal speed and temperature of the thermal treatment on the $\mathrm{TiO}_{2}$ film thickness is shown in Figure 1. The coating thickness increases with the increase of the withdrawal speed, which is in agreement with the Landau-Levich model [17]. The film thickness is reduced for all withdrawal speeds when the heating temperature is increased. This is consistent with the fact that in this temperature range water and organic groups are removed from the titania films.

\subsection{FTIR Spectroscopy: Withdrawal Speed}

Figure 2 shows a typical infrared spectrum of all the produced films, except for those prepared using $60 \mathrm{~mm} /$ min and heated to $400^{\circ} \mathrm{C}$.

The broad absorption band centered at $3300 \mathrm{~cm}^{-1}$ is attributed to stretching vibrations of molecular water and $\mathrm{OH}$ groups [18]. Superimposed onto this band, two other bands are clearly visible at $3365 \mathrm{~cm}^{-1}$ and $3257 \mathrm{~cm}^{-1}$. These two bands have been ascribed, respectively, to the asymmetric and symmetric stretching vibration of N-H groups from diethanolamine. Additional peaks are noted at $2930 \mathrm{~cm}^{-1}\left(\mathrm{CH}_{2}\right.$ asymmetric stretching mode $)$ and at $2867 \mathrm{~cm}^{-1}\left(\mathrm{CH}_{2}\right.$ symmetric stretching mode $)$ of the al-

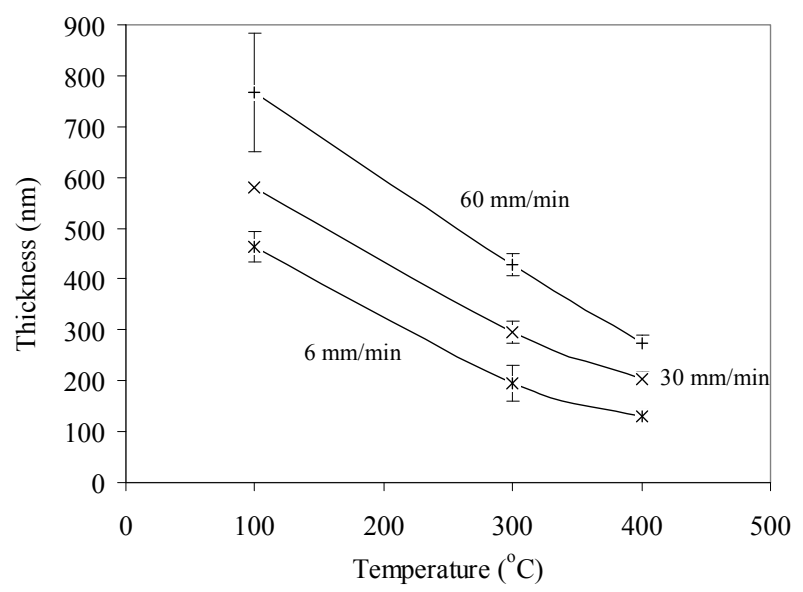

Figure 1. Thickness variation of the titania films deposited with different withdrawal speeds as a function of the heating temperature. 


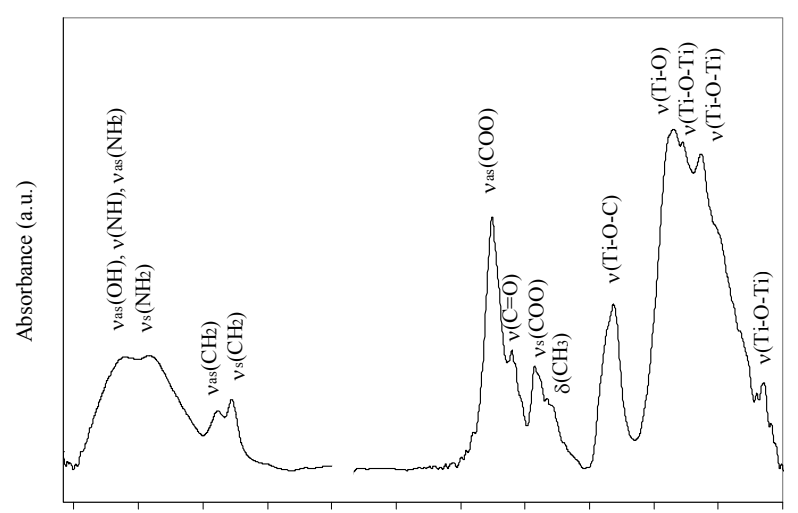

$\begin{array}{llllllllllll}3600 & 3300 & 3000 & 2700 & 2400 & 2100 & 1800 & 1500 & 1200 & 900 & 600 & 300\end{array}$ Wavenumber $\left(\mathrm{cm}^{-1}\right)$

Figure 2. Infrared spectrum $\left(\theta=80^{\circ}\right)$ of sol-gel titania film deposited at $30 \mathrm{~mm} / \mathrm{min}$ and heated to $400^{\circ} \mathrm{C}$. $v_{\text {as }}=$ asymmetric stretching mode; $v_{\mathrm{s}}=$ symmetric stretching mode; $\delta$ = angular deformation mode.

coxide [19,20].

Even in films heated up to $100^{\circ} \mathrm{C}$ the band around $1750-1735 \mathrm{~cm}^{-1}$, characteristic of the stretch vibration of the $\mathrm{C}=\mathrm{O}$ bonds of free carboxylic acids, is absent. This excludes the presence of an ester from the reaction of titanium isopropoxide with acetic acid in the sol-gel coating [20].

According to Urlaub et al. [20] and Venz et al. [21], three coordination modes of carboxylic acids to a metal atom are possible, namely monodentate via one oxygen atom, bidendate chelating via both oxygen atoms, and bidendate bridging between two metal atoms (see Figure 3).

The absorption bands at $1638 \mathrm{~cm}^{-1}$ and $1445 \mathrm{~cm}^{-1}$ are assigned respectively to the asymmetric $v_{\text {as }}(\mathrm{COO})$ and symmetric $v_{\mathrm{s}}(\mathrm{COO})$ stretching vibrations. The presence of these two bands suggests a bidentate bridging coordination for the acid group [22]. The separation of 193 $\mathrm{cm}^{-1}$ observed for the $v_{\mathrm{as}}(\mathrm{COO})$ and $v_{\mathrm{s}}(\mathrm{COO})$ peak positions is typical for bidentate bridged carboxylic acid titanium complexes [22].

The band at $1080 \mathrm{~cm}^{-1}$ is assigned to the $v(\mathrm{Ti}-\mathrm{O}-\mathrm{C})$ bridging vibrations of isopropoxy groups [20,23]. On adding nucleophilic ligands like acetic acid to titanium isopropoxide, the coordination number of the central atom increases from 4 to 6 and oligomeric species $\left[\left(\mathrm{Ti}\left(\mathrm{OPr}^{i}\right)_{3}(\mathrm{OAc})\right]_{n}(n=2\right.$ or 3$)$ are formed [16]. In bidentate bridging coordinations, the isopropoxy groups are present between two titanium atoms. Our results suggest the formation of a dimeric complex, with the acetic acid acting as a carboxylate ligand, $\left(\mathrm{CH}_{3} \mathrm{COO}^{-}\right)$. The structure complex suggested (see Figure 4) is in agreement with the literature [19,24,25].

Unlike the other samples, the films deposited at 60 $\mathrm{mm} / \mathrm{min}$ and heated to $400^{\circ} \mathrm{C}$ do not exhibit the characteristic peaks of the isopropoxy bridging group. In this case, the complex should have the structure proposed in Figure 5, where the titanium atoms are pentacoordinated. Urlaub et al. [20] suggested the same type of structure in complexes formed by titanium isopropoxide and transpropene-1,2,3-tricarboxilic acid, and also mention the existence of another complex of titanium pentacoordinated titanium.

The bands related to the $v_{\mathrm{as}}(\mathrm{COO})$ and $v_{\mathrm{s}}(\mathrm{COO})$ vibrations, which indicate the coordination mode of the acetate group in the titanium alcoxide and thus the structure of the molecule formed, are relatively large and may represent the convolutions of two or more signals. This feature is an indication that other different binding modes of acetate group are present.

Additional bands were observed at $1560 \mathrm{~cm}^{-1}, 1380$ $\mathrm{cm}^{-1}$, and $1263 \mathrm{~cm}^{-1}$. The bands at $1560 \mathrm{~cm}^{-1}$ and 1263 $\mathrm{cm}^{-1}$ are due to the respective $v(\mathrm{C}=\mathrm{O})$ and $\delta(\mathrm{CO})$ modes [20]. The band at $1380 \mathrm{~cm}^{-1}$ is caused by the symmetric deformation band of a $\mathrm{CH}_{3}$ group from the isopropoxide structure $[19,26]$.

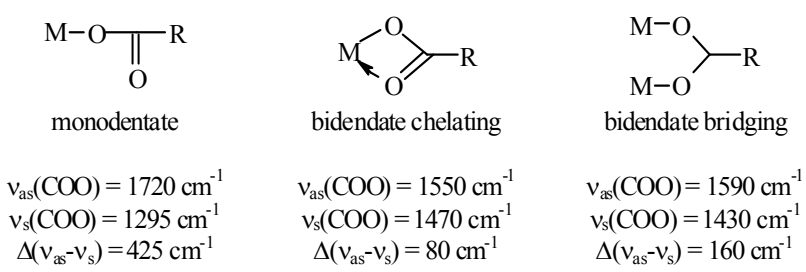

Figure 3. Possible coordination modes in metal carboxilates.

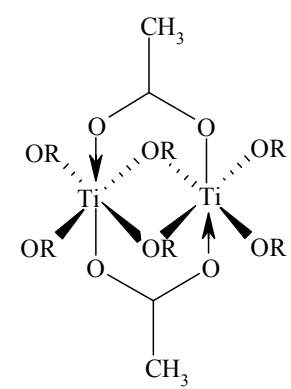

Figure 4. Proposed structure for the complex of titanium isopropoxide and acetic acid.

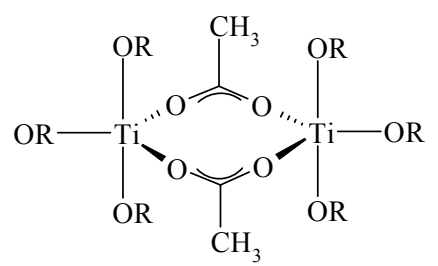

Figure 5. Proposed structure of the complex titanium isopropoxide-acetic acid for the sol-gel films deposited at 60 $\mathrm{mm} / \mathrm{min}$ and heated to $400^{\circ} \mathrm{C}$. 
It was observed that the bands at $1000 \mathrm{~cm}^{-1}$ and 850 $\mathrm{cm}^{-1}$ are not present in the infrared spectra of the coatings produced. The band at $1000 \mathrm{~cm}^{-1}$ is related to transition metal isopropoxides ( $r(\mathrm{CO})$ mode) and to the isopropoxide group (C-C skeleton vibration). The peak at $850 \mathrm{~cm}^{-1}$ is also related to the isopropoxide group. The absence of these two bands in the infrared spectra of the coatings produced strongly suggests that the titanium isopropoxide has been consumed during the sol preparation [19].

The only two products of the hydrolysis reaction are the titanium hydroxide and the isopropanol. No band can be clearly associated to the $\mathrm{Ti}-\mathrm{OH}$ group, suggesting that the condensation occurred immediately after the hydrolysis of the titanium alcoxide. The bands for Ti-O and Ti-O-Ti bonds are present in the $800-400 \mathrm{~cm}^{-1}$ region, the former being observed in a higher wavenumber than the latter $[19,23]$. The titania sol-gel films produced in this work show an infrared band around $805 \mathrm{~cm}^{-1}$ related to the $v$ (Ti-O) mode. The bands at $760 \mathrm{~cm}^{-1}, 680 \mathrm{~cm}^{-1}$, $560 \mathrm{~cm}^{-1}, 500 \mathrm{~cm}^{-1}, 468 \mathrm{~cm}^{-1}, 410 \mathrm{~cm}^{-1}, 385 \mathrm{~cm}^{-1}$ and $350 \mathrm{~cm}^{-1}$ are associated to $v$ (Ti-O-Ti) vibrations [27-32].

The peak around $800 \mathrm{~cm}^{-1}$ is assigned to a $v(\mathrm{Ti}-\mathrm{O}) \mathrm{vi}$ bration, where the oxygen atom is in the non-binding condition. The peaks at $760 \mathrm{~cm}^{-1}, 680 \mathrm{~cm}^{-1}, 600 \mathrm{~cm}^{-1}$, $560 \mathrm{~cm}^{-1}, 500 \mathrm{~cm}^{-1}, 468 \mathrm{~cm}^{-1}, 410 \mathrm{~cm}^{-1}, 385 \mathrm{~cm}^{-1}$ and $350 \mathrm{~cm}^{-1}$ are assigned to the 1 (Ti-O-Ti) stretching vibration [27-31].

\subsection{FTIR Spectroscopy: Effects of Incidence Angle $(\theta)$ and Heat Treatment Temperature}

The variation of the incidence angle in the infrared reflection-absorption spectroscopy allows the analysis of the film's surface and depth profile. Thus, for $\theta=20^{\circ}$ and $45^{\circ}$ the inner layers of the film are considered, and for $\theta=80^{\circ}$ the surface of the film is accessed.

Figure 6 shows typical infrared spectra of titania films obtained with $\theta=80^{\circ}, 45^{\circ}$, and $20^{\circ}$ (films prepared using $6 \mathrm{~mm} / \mathrm{min}$ and heated to $400^{\circ} \mathrm{C}$ ).

The relative amount of $\mathrm{OH}, \mathrm{CH}_{2}$, and $\mathrm{CH}_{3}$ groups increases from the surface to the inner layers of the film. Besides from being sub-products of the condensation reaction, water and alcohol are also used as reagents in the film synthesis procedure. The spectra suggest that the film is more condensed near the substrate surface. If this is true, it should be expected that Ti-O-Ti bonds are generated during the condensation process and contribute to the formation of the $\mathrm{TiO}_{2}$ lattice $[19,32]$.

Figure 7 shows the intensity ratio between the hydroxyl band and the Ti-O- $\mathrm{O}^{-}$band $\left(800 \mathrm{~cm}^{-1}\right)$ as a function of the incidence angle and of the heat-treatment temperature of the film.

The amount of $\mathrm{OH}$ groups increases as the incidence

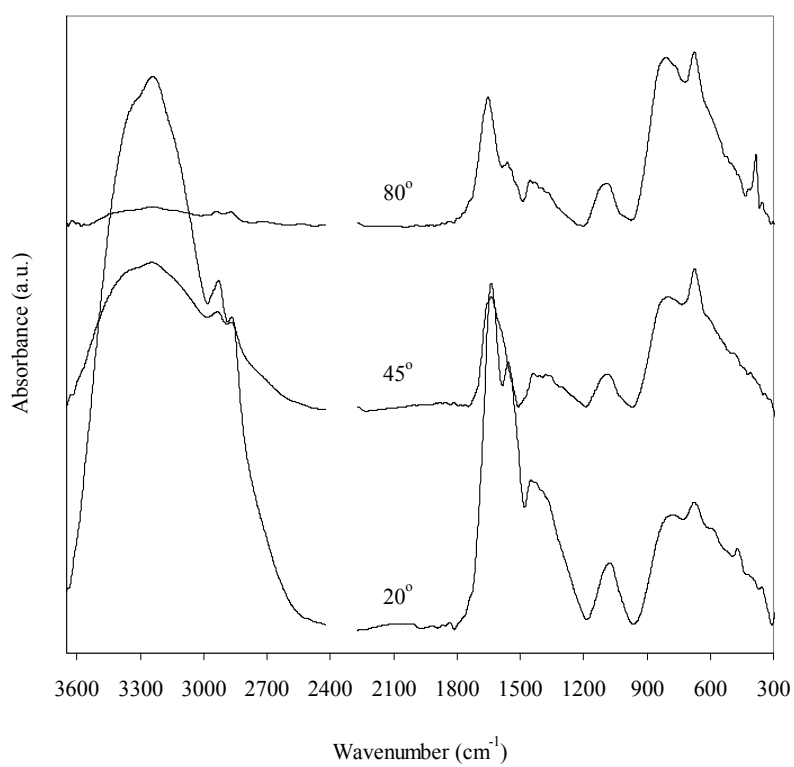

Figure 6. Infrared spectra $\left(\theta=80^{\circ}, 45^{\circ}\right.$, and $\left.20^{\circ}\right)$ of sol-gel titania film deposited at $6 \mathrm{~mm} / \mathrm{min}$ and heated to $400^{\circ} \mathrm{C}$.

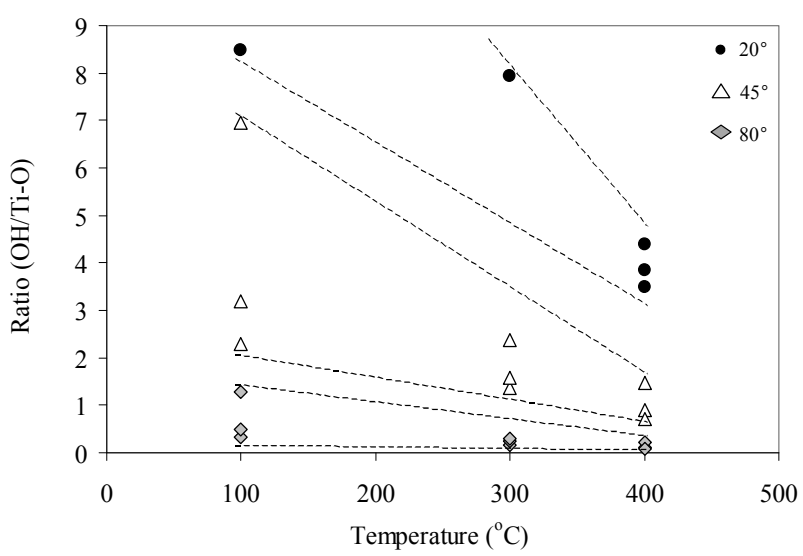

Figure 7. Evolution of the absorbance intensity ratio of $\mathrm{OH} /$ Ti-O peaks with $\theta$ and temperature.

angle $(\theta)$ is reduced. Also, the content of $\mathrm{OH}$ groups decreases for increasing heating temperatures.

The intensity ratio between the Ti-O-Ti band $\left(680 \mathrm{~cm}^{-1}\right)$ and the Ti-O band $\left(800 \mathrm{~cm}^{-1}\right)$ as function of the incidence angle and of the heating temperature of the films is shown in Figure 8. This intensity ratio increases when the incidence angle changes from $80^{\circ}$ to $45^{\circ}$, indicating that Ti-O-Ti bonds are formed at the expense of Ti-O bonds. This result suggests a more condensed structure in the inner part of the sample.

Table 1 gives the corresponding wavenumbers of Ti-O and Ti-O-Ti vibrational modes as function of the incidence angle and of the heating temperature. The separation $\left(\Delta_{(\mathrm{Ti}-\mathrm{O})-(\mathrm{Ti}-\mathrm{O}-\mathrm{Ti})}\right)$ between the Ti-O and Ti-O-Ti bands increases when the heating temperature is increased. 
Table 1. IR absorption wavenumbers $\left(\mathrm{cm}^{-1}\right)$ of the Ti-O e Ti-O-Ti vibrational modes for different temperatures and IR incidence angles $(\theta)$.

\begin{tabular}{|c|c|c|c|c|c|c|}
\hline \multirow{3}{*}{ Temperature } & \multicolumn{6}{|c|}{ Wavenumber $\left(\mathrm{cm}^{-1}\right)$} \\
\hline & \multicolumn{3}{|c|}{$80^{\circ}$} & \multicolumn{3}{|c|}{$45^{\circ}$} \\
\hline & Ti-O & Ti-O-Ti & $\Delta_{\text {(Ti-O)-(Ti-O-Ti) }}$ & Ti-O & Ti-O-Ti & $\Delta_{(\mathrm{Ti}-\mathrm{O}) \text {-(Ti-O-Ti) }}$ \\
\hline $100^{\circ} \mathrm{C}$ & $795 \pm 2$ & $687 \pm 5$ & 109 & & & \\
\hline $300^{\circ} \mathrm{C}$ & $815 \pm 10$ & $680 \pm 1$ & 135 & $796 \pm 3$ & $673 \pm 1$ & 122 \\
\hline $400^{\circ} \mathrm{C}$ & $824 \pm 10$ & $684 \pm 4$ & 140 & $816 \pm 10$ & $675 \pm 2$ & 141 \\
\hline
\end{tabular}

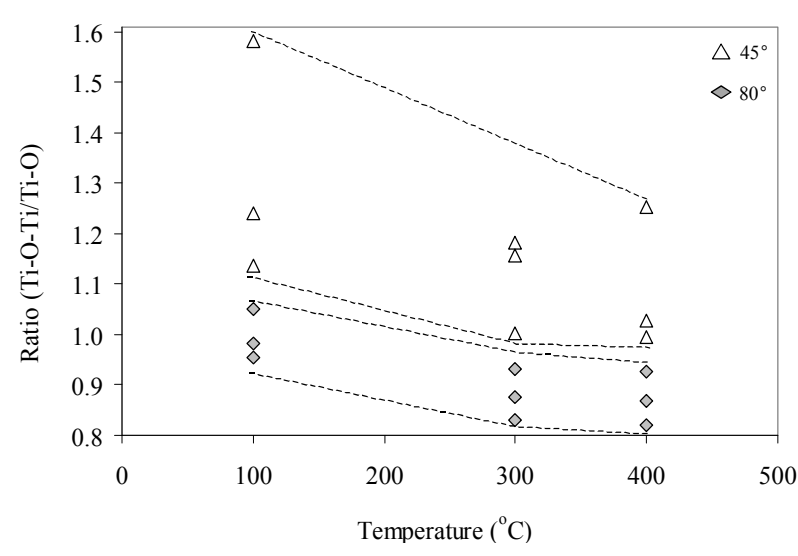

Figure 8. Evolution of the absorbance intensity ratio of Ti-O-Ti/Ti-O peaks with $\theta$ and temperature.

From Figure 9 it can be seen that the Ti-O band is more affected by heating than the Ti-O-Ti band. The shifting of the Ti-O band to higher wavenumbers is related with the formation of stronger bonds and with the generation of a more resistant film.

For the same final temperature of heating, the separation between the peaks tends to decrease from the surface towards the interior of the film mainly due to the reducetion in the intensity of the Ti-O band. This band is absent for $\theta=45^{\circ}$ in films dried to $100^{\circ} \mathrm{C}$, and in all films for $\theta$ $=20^{\circ}$. Again, the hypothesis that the interior of the film has a more developed titanium oxide network is supported by our experimental results. As shown in Figure 10, only the films deposited at $60 \mathrm{~mm} / \mathrm{min}$ and heated to $400^{\circ} \mathrm{C}$ have a well-defined Ti-O band for $\theta=20^{\circ}$.

\subsection{Glow Discharge Spectrometry-GDS}

The composition depth profile of the sol-gel titania films, prepared with ethanol/TIP $=16$, were evaluated by GDS. The intensity of the detected signal is proportional to the amount of the element present in the plasma, which is controlled by the concentration in the samples and by the sputter rate. The intensities of $\mathrm{O}, \mathrm{Mn}$ and $\mathrm{Si}$ have been normalized for each sample by multiplying the signal by 10,5 and 2, respectively, so that all the element profiles

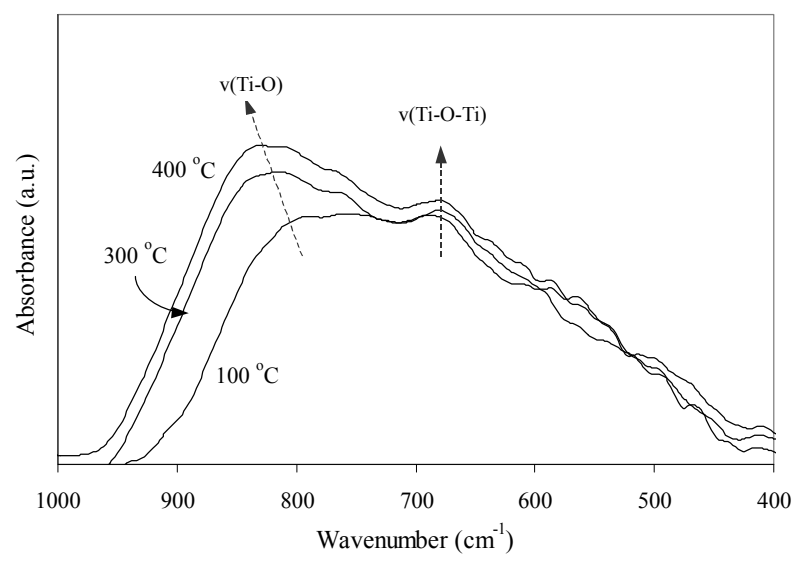

Figure 9. Infrared spectra $\left(\theta=80^{\circ}\right)$ of sol-gel titania film deposited at $30 \mathrm{~mm} / \mathrm{min}$ and heated to $100^{\circ} \mathrm{C}, 300^{\circ} \mathrm{C}$ and $400^{\circ} \mathrm{C}$.

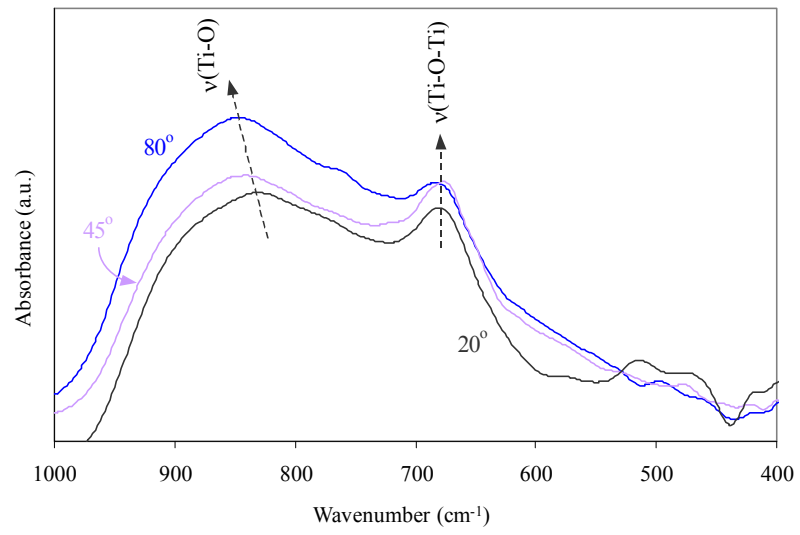

Figure 10. Shift of the bands attributed to Ti-O and Ti-O-Ti vibrations in relation to $\theta$.

could be presented in the same figures.

Figures 11 to 14 show the chemical depth profile of the composites obtained from films deposited at withdraw speeds of $6 \mathrm{~mm} / \mathrm{min}, 30 \mathrm{~mm} / \mathrm{min}$ and $60 \mathrm{~mm} / \mathrm{min}$ and heat-treated at $300^{\circ} \mathrm{C}$ and $400^{\circ} \mathrm{C}$. Since the depths on the graphs are obtained by multiplying the time data by the average sputter rate, their values are approximate. 


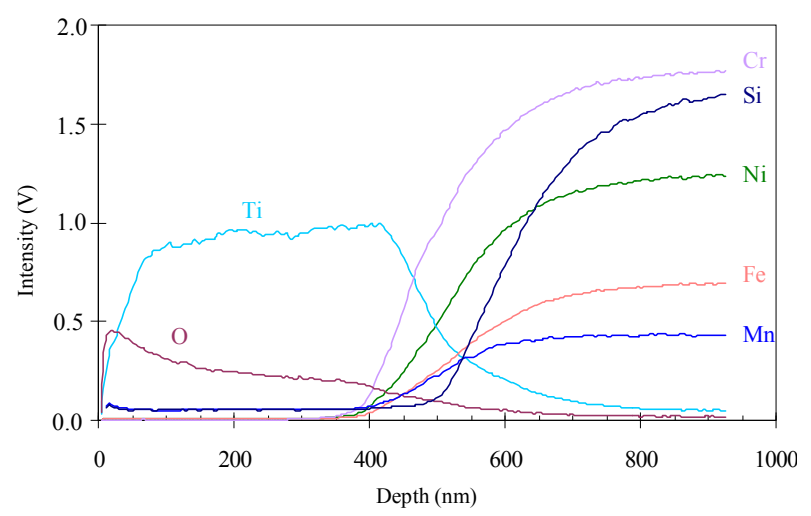

Figure 11. GDS of a titania sol-gel film deposited at $30 \mathrm{~mm} /$ min and heated at $300^{\circ} \mathrm{C}$.

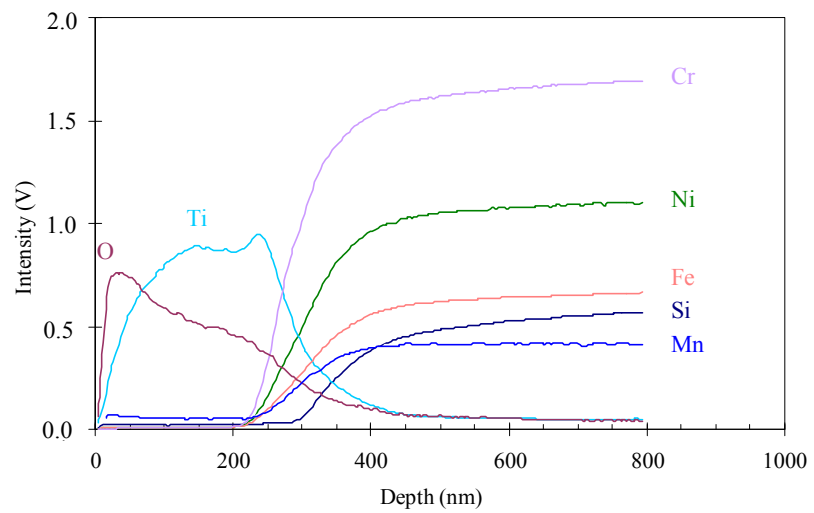

Figure 12. GDS of a titania sol-gel film deposited at $6 \mathrm{~mm} /$ min and heated at $400^{\circ} \mathrm{C}$.

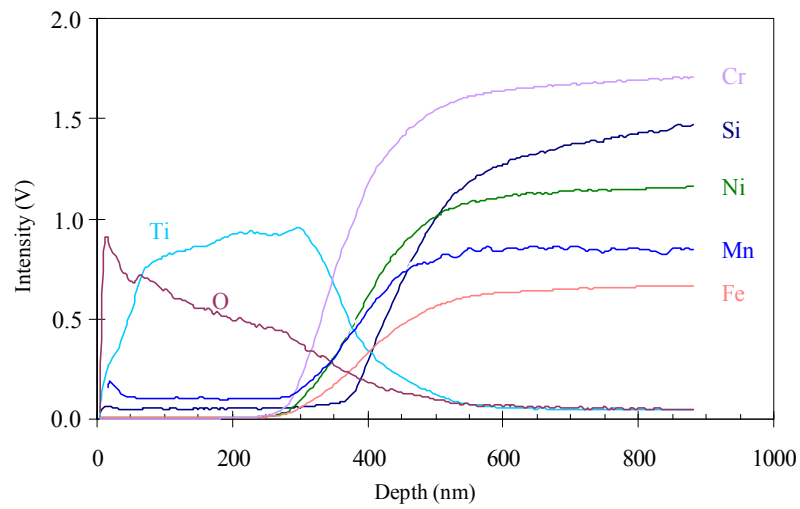

Figure 13. GDS of a titania sol-gel film deposited at $30 \mathrm{~mm} /$ min and heated at $400^{\circ} \mathrm{C}$.

The thicknesses of the sol-gel films were estimated from the depth profile of $\mathrm{Ti}$, considering the interval where the intensity of Ti begins to decline, and the intensity of $\mathrm{Cr}$ (first detected element of the substrate) becomes significant. The approximate thicknesses of the titania sol-gel films were $420 \mathrm{~nm}$ for the composite ob-

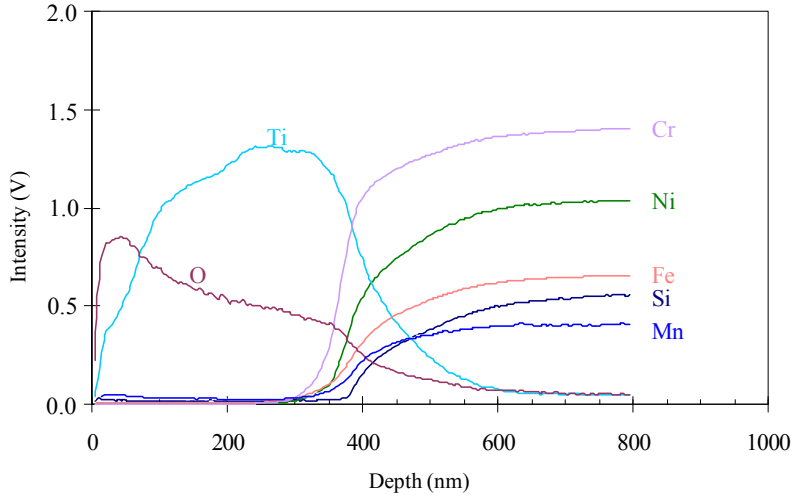

Figure 14. GDS of a titania sol-gel film deposited at $60 \mathrm{~mm} /$ min and heated at $400^{\circ} \mathrm{C}$.

tained at $30 \mathrm{~mm} / \mathrm{min}$ and $300^{\circ} \mathrm{C}$ (Figure 11), and $260 \mathrm{~nm}$ $(6 \mathrm{~mm} / \mathrm{min}$, Figure 12), $320 \mathrm{~nm}(30 \mathrm{~mm} / \mathrm{min}$, Figure 13) and $360 \mathrm{~nm}(60 \mathrm{~mm} / \mathrm{min}$, Figure 14) for the composites heated to $400^{\circ} \mathrm{C}$. These results are in agreement with those from the literature showing that the increase of the withdraw speed led to the formation of thicker films while an increase in the drying temperature reduces the film's thickness.

The intensity of the observed emissions is a combination of the concentration of the analyzed elements and of the rate of sputtering/excitation in the plasma. Thus, in a given sample the intensity of $\mathrm{Fe}$, which is the most abundant element in stainless steel, is lower than the intensity of the other elements that make up the alloy, such as Cr. The explanation for this apparent paradox is that $\mathrm{Cr}$ has a higher sensitivity to the used wavelength than $\mathrm{Fe}$. Also, the response difference among the sensors used in this technique for the different elements must also be considered. Thus, a rigorous quantitative analysis requires the use of reference standards. Considering, however, that all the samples have nominally the same composition and that the conditions of discharge are the same for each profile, the intensity detected should be representative of actual concentrations, making it possible to compare different samples.

In all analyzed samples the increase of the Ti signal is gradual. This result confirms a lower Ti concentration in the film surface. The increase in Ti content corresponds to a decrease in the oxygen profile.

The composite obtained from the withdraw speed of $60 \mathrm{~mm} / \mathrm{min}$ and heated to $400^{\circ} \mathrm{C}$ (Figure 14) shows the highest Ti intensity. In all other composites, the intensity of Ti is similar of that observed for the Ni from the substrate. This is an important indication that in the composite shown in Figure 14, either the Ti content in the solgel film is quite high, or this film has a much higher density than the others. Indeed, as discussed before with the 
results obtained by FTIR, the sol-gel film of this composite has a different structure when compared to the others.

By using the Knoop microindentation hardness tests, we observed that the titania film heat treated to $400^{\circ} \mathrm{C}$ shows a higher hardness value $(410 \mathrm{GPa})$ than steel $(330$ $\mathrm{GPa}$ ). This is consistent with the interpretation of the GDS results, indicating that this film in particular shows the highest $\mathrm{Ti}$ concentration in the outermost surface.

\section{Conclusions}

Thin films of titania deposited on $316 \mathrm{~L}$ stainless steel have been prepared using the sol-gel method. The infrared reflectance-absorbance spectra indicated the formation of a dimeric complex in a bidantate bridging coordination between the titanium isopropoxide and the acetic acid. According to the processing conditions of the film, the titanium atoms can also be present as pentacoordinated. We have established a qualitative procedure for the investigation of the film structure by changing the beam incidence angle in the infrared experiments. We observed that the relative amounts of $\mathrm{OH}, \mathrm{CH}_{2}$, and $\mathrm{CH}_{3}$ groups increase from the surface to the inner layers of the film, indicating that the films are more condensed near the substrate surface. The composite prepared with withdraw speed of $60 \mathrm{~mm} / \mathrm{min}$ and heated to $400^{\circ} \mathrm{C}$ has the highest Ti content. By using the Knoop microindentation hardness test, we observed that this titania film, when heat treated, tended to be harder than the steel substrate.

\section{Acknowledgements}

The authors acknowledge financial support from the Minas Gerais Research Agency (Fapemig), Brazilian Research Agency (CNPq), Brazilian Graduate Agency (CAPES), Minerals and Metallurgy Pole of Excellence of The Minas Gerais State, and The National Institute of Science and Technology on Mineral Resources, Water, and Biodiversity (Acqua).

\section{REFERENCES}

[1] Y. Xu, C. J. Chen, R. Xu and J. D. Mackenzie, "Ferroelectric $\mathrm{Sr}_{0.60} \mathrm{Ba}_{0.40} \mathrm{Nb}_{2} \mathrm{O}_{6}$ Thin Films by the Sol-Gel Process: Electrical and Optical Properties," Physical Review $B$, Vol. 44, No. 1, 1991, pp. 35-41. doi:10.1103/PhysRevB.44.35

[2] B. D. Fabes, B. J. J. Zelinski and D. R. Uhlmann, "SolGel Ceramic Coatings," In: J. B. Wachtman and R. A. Haber, Eds., Ceramic Films and Coatings, Noyes Publication, Saddle River, 1993, pp. 224-283.

[3] A. Yasumori, H. Shinoda, Y. Kameshima, S. Hayashi and K. Okada, "Photocatalytic and Photoelectrochemical Properties of $\mathrm{TiO}_{2}$-Based Multiple Layer Thin Film Prepared by Sol-Gel and Reactive-Sputtering Methods," Journal of
Materials Chemistry, Vol. 11, No. 4, 2001, pp. 1253-1257. doi:10.1039/b100216n

[4] L. L. Hench and W. L. Vasconcelos, "Sol-Gel Silica Science," Annual Review in Materials Science, Vol. 20, 1990, pp. 269-298. doi:10.1146/annurev.ms.20.080190.001413

[5] C. McDonagh, F. Sheridan, T. Butler and B. D. MacCraith, "Characterisation of Sol-Gel-Derived Silica Films," Journal of Non-Crystalline Solids, Vol. 194, No. 1-2, 1996, pp. 72-77. doi:10.1016/0022-3093(95)00488-2

[6] K. Izumi, N. Minami and Y. Uchida, "Sol-Gel Derived Coatings on Steel Sheets," Key Engineering Materials, Vol. 150, 1998, pp. 77-88.

doi:10.4028/www.scientific.net/KEM.150.77

[7] J. Oh, H. Imai and H. Hirashima, "Direct Deposition of Silica Films Using Silicon Alkoxide Solution," Journal of Non-Crystalline Solids, Vol. 241, No. 2-3, 1998, pp. 91-97. doi:10.1016/S0022-3093(98)00772-8

[8] H. Ohsaki and Y. Kokubu, "Global Market and Technology Trends on Coated Glass for Architectural, Automotive and Display Applications," Thin Solid Films, Vol. 351, No. 1-2, 1999, pp. 1-7. doi:10.1016/S0040-6090(99)00147-9

[9] L. M. Sheppard, "Sol-Gel: Making Its Way into the Mainstream," Photonics Spectra, Vol. 34, No. 1, 2000, pp. 128-132.

[10] D. C. L. Vasconcelos, J. A. N. Carvalho, M. Mantel and W. L. Vasconcelos, "Corrosion Resistance of Stainless Steel Coated with Sol-Gel Silica," Journal of Non-Crystalline Solids, Vol. 273, No. 1-3, 2000, pp. 135-139. doi:10.1016/S0022-3093(00)00155-1

[11] T. Lampke, S. Darwich, D. Nickel and B. Wielage, "Development and Characterization of Sol-Gel Composite Coatings on Aluminum Alloys for Corrosion Protection," Materialwissenschaft und Werkstofftechnik, Vol. 39, No. 12, 2008, pp. 914-919. doi:10.1002/mawe.200800396

[12] T. Gichuhi, A. Balgeman, A. Adams and S. Prince, "Hybrid Sol-Gel Corrosion Inhibitors: A Novel Approach to Corrosion Inhibitorsfor Coating," Journal of Coatings Technology, Vol. 6, No. 4, 2009, pp. 24-29.

[13] G. Tsaneva, V. Kozhukharov, S. Kozhukharov, M. Ivanova, J. Gerwann, M. Schem and T. Schmidt, "Functional Nanocomposite Coatings for Corrosion Protection of Aluminum Alloy and Steel," Journal of the University of Chemical Technology and Metallurgy, Vol. 43, No. 2, 2008, pp. 231-238.

[14] M. Guglielmi, "Sol-Gel Coatings on Metals," Journal of Sol-Gel Science and Technology, Vol. 8, No. 1-3, 1997, pp. 443-449. doi:10.1007/BF02436880

[15] K. Izumi, N. Minami and Y. Uchida, "Sol-Gel-Derived Coatings on Steel Sheets," Key Engineering Materials, Vol. 150, 1998, pp. 77-88. doi:10.4028/www.scientific.net/KEM.150.77

[16] M. Atik, S. H. Messaddeq, F. P. Luna and M. A. Aegerter, "Zirconia Sol-Gel Coatings Deposited on 304 and 316L Stainless Steel for Chemical Protection in Acid Media," Journal of Materials Science Letters, Vol. 15, No. 23, 1996, pp. 2051-2054. 
[17] L. Landau and B. Levich, "Dragging of a Liquid by a Moving Plate," Acta Physicochimica U.R.S.S., Vol. 17, No. 1-2, 1942, pp. 42-54.

[18] D. L. Wood, E. M. Rabinovich, D. W. Johnson Jr., J. B. Mac-Chesney and E. M. Vogel, "Preparation of High-Silica Glasses from Colloidal Gels. 3. Infrared Spectrophotometric Studies," Journal of the American Ceramic Society, Vol. 66, No. 10, 1983, pp. 693-699. doi:10.1111/j.1151-2916.1983.tb10531.x

[19] M. Burgos and M. Langlet, "The Sol-Gel Transformation of TIPT Coatings: A FTIR Study," Thin Solid Films, Vol. 349, No. 1-2, 1999, pp. 19-23. doi:10.1016/S0040-6090(99)00139-X

[20] R. Urlaub, U. Posset and R. Thull, "FT-IR Spectroscopic Investigations on Sol-Gel-Derived Coatings from AcidModified Titanium Alkoxides," Journal of Non-Crystalline Solids, Vol. 265, No. 3, 2000, pp. 276-284. doi:10.1016/S0022-3093(00)00003-X

[21] P. A. Venz, R. L. Frost and J. T. Kloprogge, "Chemical Properties of Modified Titania Hydrolysates," Journal of Non-Crystalline Solids, Vol. 276, No. 1-3, 2000, pp. 95112. doi:10.1016/S0022-3093(00)00267-2

[22] S. Doeuff, M. Henry, C. Sanchez and J. Livage, "Hydrolysis of Titanium Alkoxides: Modification of the Molecular Precursor by Acetic Acid," Journal of Non-Crystalline Solids, Vol. 89, No. 1-2, 1987, pp. 206-216. doi:10.1016/S0022-3093(87)80333-2

[23] F. N. Castellano, J. M. Stipkala, L. A. Friedman and G. L. Meyer, "Spectroscopic and Excited-State Properties of Titanium-Dioxide Gels," Chemistry of Materials, Vol. 6, No. 11, 1994, pp. 2123-2129. doi:10.1021/cm00047a037

[24] C. Sanches, F. Babonneau, S. Doeuff and A. Leaustic, "Chemical Modifications of Titanium Alkoxide Precursors," In: J. D. Mackenzie and D. R. Ulrich, Eds., Ultrastructure Processing of Advanced Materials, John Wiley,
New York, 1988, pp. 77-78.

[25] C. J. Brinker and G. W. Scherer, "Sol-Gel Science: The Physics and Chemistry of Sol-Gel Processing," Academic Press, New York, 1990.

[26] D. P. Birnie, "Esterification Kinetics in Titanium Isopropoxide-Acetic Acid Solutions," Journal of Materials Science, Vol. 35, No. 2, 2000, pp. 367-374. doi:10.1023/A:1004770007284

[27] Y. Djaoued, S. Badilescu, P. V. Ashrit and J. Robichaud, "Vibrational Properties of the Sol-Gel Prepared Nanocrystalline $\mathrm{TiO}_{2}$ Thin Films," The Internet Journal of Vibrational Spectroscopy, Vol. 5, Section 4, 2001. http://www.ijvs.com/archive.html

[28] M. Crisan, M. Zaharescu, A. Jitianu, D. Crisan and M. Preda, "Sol-Gel Poly-Component Nano-Sized Oxide Powders," Journal of Sol-Gel Science and Technology, Vol. 19, No. 1-3, 2000, pp. 409-412. doi:10.1023/A:1008735127136

[29] H. Izutsu, P. K. Nair, K. Maeda, Y. Kiyozumi and F. Mizukami, "Structure and Properties of $\mathrm{TiO}_{2}-\mathrm{SiO}_{2}$ Prepared by Sol-Gel Method in the Presence of Tartaric Acid," Materials Research Bulletin, Vol. 32, No. 9, 1997 , pp. 1303-1311. doi:10.1016/S0025-5408(97)00106-2

[30] D. C. Bradley, R. C. Mehrotra and D. P. Gaur, "Metal Alkoxides," Academic Press, New York, 1978.

[31] C. M. Phillippi and S. R. Lyon, "Longitudinal-Optical Phonons in $\mathrm{TiO}_{2}$ (Rutile) Thin-Film Spectra," Physical Review B, Vol. 3, No. 6, 1971, pp. 2086-2087. doi:10.1103/PhysRevB.3.2086

[32] S. Musić, M. Gotić, M. Ivanda, S. Popović, A. Turković, R. Trojko, A. Sekulić and K. Furić, "Chemical and Microstructural Properties of $\mathrm{TiO}_{2}$ Synthesized by Sol-Gel Procedure," Materials Science and Engineering B, Vol. 47, No. 1, 1997, pp. 33-40. doi:10.1016/S0921-5107(96)02041-7 